\title{
The Processual Intertextuality of Literary Cartographies: \\ Critical and Digital Practices
}

\section{David Cooper and Gary Priestnall}

\author{
Authors: \\ Dr David Cooper, Department of English \& Creative Writing, County College, Lancaster \\ University, LA1 4YD, UK. \\ E-mail: d.cooper1@lancaster.ac.uk
}

Dr Gary Priestnall, School of Geography, University of Nottingham, NG7 2RD, UK.

E-mail: gary.priestnall@nottingham.ac.uk

\begin{abstract}
:
Drawing upon recent interdisciplinary research in the fields of literary geography and critical cartography, this article argues that a concept of processual intertextuality might be used to open up thinking about literary maps and mapping practices: a concept through which such maps are understood to be systems of cultural signification which are inextricably embedded within the material world and which are brought-into-being with each embodied reading or use. This theory is then applied to maps which are both reproduced within and generated by Arthur Ransome's Swallows and Amazons (1930): an adventure novel for children which is predicated upon a conflation of actual and imagined geographies. The article goes on to propose that the critical understanding of the processual intertextuality of literary cartographies might be further enhanced by the use of a suite of geo-location technologies; and, ultimately, it suggests that the future of critical literary cartography might be founded, at least in part, upon in-the-field digital mapping practices.
\end{abstract}

Keywords: critical literary geography, authorial and reader-generated mappings, processual intertextuality, Lake District, Arthur Ransome, literary fieldwork, digital mapping practices. 


\section{Introduction: Authorial and Reader-Generated Mappings}

In a key positional essay published in New Formations in 2005/6, Andrew Thacker traces 'a brief genealogy' of spatial literary criticism and interrogates the conceptual possibilities (and problems) associated with a methodology he labels 'critical literary geography' (Thacker, 2005/6, p. 56). Thacker begins his exploration of this interdisciplinary paradigm by acknowledging the proliferation of mapping metaphors and strategies within literary studies and, more generally, across the humanities and social sciences: a proliferation which can perhaps be traced back to Frederic Jameson's preoccupation with 'cognitive mapping' (Thacker, 2005/6, p. 57). For Thacker, however, a critical literary geography ought to be predicated, at least in part, upon consideration of cartographic theory, practices and processes. That is to say, there is a need to acknowledge the helpful malleability of the mapping metaphor but, at the same time, to think more precisely about the synergies and tensions between textual and cartographic representations of geographical space. If the spatial critic is to act upon Thacker's prompt, then, it is possible to place his or her critical practice in two broadly defined categories: authorial and reader-generated mappings. ${ }^{1}$ First of all, he or she may read authorial maps: those cartographic representations of space which are embedded within the published text but which are, more often than not, 'seemingly peripheral [para]textual features to the central narrative' (Thacker, 2005/6, p. 64). By extension, he or she may she wonder about 'the epistemological status of such pictorial maps that accompany writing' (Thacker, 2005/6, p. 64). ${ }^{2}$ Alternatively, the critic may follow the exploratory example set by Franco Moretti in order to produce his or her own maps: literary cartographies based upon the spatial interpretation of a particular text or texts (Moretti, 1998). In spite of the differing emphases, the spatial critic, in both cases, moves away from metaphorical mapping to consider the complex imaginative geographies produced by planesurface cartographies and, by extension, to reflect upon the relationship between textual and mapped space.

This article seeks to showcase these interrelated forms of critical practice through an exploration of the Lake District literary cartography famously associated with the twentiethcentury English children's novelist, Arthur Ransome (1884-1967). In one sense, we are concerned with articulating a concept of processual intertextuality with which to facilitate further thinking about the readerly engagement with the authorial maps published in 
Ransome's most celebrated work of Lakeland fiction, Swallows and Amazons (1930). At the same time, however, we are interested in how this theory of processual intertextuality might be productively applied to reader-generated cartographic retracings of Ransome's imaginative geographies. Part of this paper, then, is dedicated to a theorised engagement with the work of, and extant spatial responses to, this key literary map-maker. The critical emphasis of the article is then recalibrated, though, to focus upon the ways in which the methodological possibilities of literary cartography might be expanded through the use of digital technologies. It is argued that the use of such technologies might aid the critical interpretation of maps embedded within published landscape writings such as Ransome's Swallows and Amazons; and, alongside this, it is suggested that access to these technologies might also point the way towards new developments in the creation of reader-generated literary maps. Crucially, the paper proposes that the interdisciplinary research of the spatial critic might be enriched through a progression from the use of Geographic Information Systems (GIS) technology to hand-held devices to be used in literary fieldwork. The latter part of this paper, therefore, is self-consciously exploratory as we suggest some ways in which the emerging field of literary cartography might be advanced through the dynamic integration of both new technologies and in-the-field research practices. Before advancing these imbricated forms of critical literary cartography, however, it is first necessary to register two cardinal ways of conceptualising maps and mapping practices

\section{Conceptualising (Literary) Cartography: Texts and Processes}

As Thacker argues, 'it seems important to return to the map as a set of material signs' (Thacker, 2005/6, p. 64): a formulation which serves as a reminder of the textuality of twodimensional cartographies. By extension, this reminder returns us to what Jess Edwards terms the 'first revolution in a critical history of cartography' which involved 'a shift from the essentially idealist habit of seeing through it [the map], as a window on the world, to one of reading it as a cultural text'; a conceptual development which was heralded by Brian Harley's readings of 'the role of maps in the cultural making of knowledge' (Edwards, 2006, pp. 3-4). As Edwards highlights, 'this new cartographic history' owed a theoretical indebtedness to 'French post-structuralism, and specifically to Michel Foucault' (Edwards, 2006, p. 4), as maps were decoded as textual sites of ideological discourse. At the root of this new form of Foucauldian critical cartography, therefore, was an understanding of the ways in which maps 
function through a process of semiotic signification; a sense of how the efficacy of the map is necessarily predicated upon the user's familiarity with, and understanding of, a system of textual (for example, in the form of place names) and symbolic representations of the textured landscape. By extension, then, maps were, and are, understood to be cultural texts which are produced within networks of intertextuality; they are created within the contexts of what might be described as the macro-intertextuality of linguistic codes and, simultaneously, the micro-intertextuality of cartographic history and convention.

In tracing the brief history of critical cartography, Edwards draws attention to a second way of conceptualising maps which emerged in response to the perceived theoretical abstraction and cultural formalism of Harley's deconstructive method (Edwards, 2006, pp. 78): a movement towards a phenomenological understanding of the embodied, experiential nature of mapping practices. Saliently, what Edwards identifies to be an intersubjective preoccupation with the phenomenology of mapping practices has emerged as, perhaps, the dominant trope within critical cultural cartography since the publication of his monograph in 2006. It is a concern which is most significantly exemplified by the processual understanding of maps and mapping practices projected by many of the essays collected in Rethinking Maps: New Frontiers in Cartographic Theory (Dodge et al, 2009). In their Introduction to this interdisciplinary collection, Kitchin et al indicate how recent research has treated 'maps not as unified representations but as constellations as ongoing processes'; in other words, they stress that there has been an emerging recognition of how 'maps are used and produced through multiple sets of practices' (Kitchin et al, 2009, p. 16). As a result, maps, map-making and map-reading are all seen to be 'embodied and dynamic' processes; a shift from 'ontology to ontogenesis' which, through an emphasis on performativity, leads to an understanding of maps 'as always in a state of becoming' (Kitchin et al, 2009, pp. 16-17) rather than absolute fixity.

By extension, then, this conceptualisation of mapping 'as a suite of cultural practices involving action and affects' (Kitchin et al, 2009, p. 17) could be seen to problematise the idea of maps as stable systems of signification in that emphasis is placed upon the singularity of each map-making and map-reading process: an argument which could be supported by Edwards's acknowledgment of the perennial difficulty of reconciling 'the tension between phenomenology and history' (Edwards, 2006, p. 10). For Kitchin et al, however, embodied processes and practices are not dehistoricised or desocialised; but, rather, maps are shown to be emplaced and unfolded within a complex concatenation of contexts. As a result, then, this 
phenomenology of cartography does not negate the proposition that maps can be understood to be texts and, by extension, intertexts. Instead, there is a need to understand the processual intertextuality of maps: an alertness to the way in which maps are produced by, and are situated within, networks of intertextual signification; yet, at the same time, a sensitivity to how that intertextual cartography continually comes-into-being with each individual, embodied and emplaced mapping practice.

[Insert Figure 1 here: OS map.]

This key concept of processual intertextuality can be illuminated by turning to a standard 1: 25,000 Ordnance Survey Explorer Map used for rambling through, say, the southwestern area of the English Lakes (see Figure 1). The production of this map is predicated upon the Ordnance Survey's self-conscious engagement with two imbricated types of cartographic intertextuality. First, the map has been deliberately produced within the cultural context provided by earlier cartographic representations of geographical space (including, of course, the Ordnance Survey's own earlier mapping practices): an intertextuality which is evidenced by the use of cartographic convention such as scale and symbology. In making this Explorer Map, therefore, the Ordnance Survey has purposefully drawn upon - and implicitly alluded to - previous map-making practices and cartographic customs. Second, the map has been produced within a geo-specific intertextual context. That is to say, in making this cartography, the Ordnance Survey has consulted, and built upon, earlier mappings of the south-west corner of the English Lake District.

Although such intertextual references and allusions may be encoded within the representational features of the map, however, a map user is necessarily required, of course, in order to bring this network of associations into being; and, crucially, that user is a phenomenological body inextricably emplaced within the material world. When the map is brought-into-being through everyday use, the associative network can expand far beyond those cartographical intertexts self-consciously invoked and utilised by the map-makers. In other words, the individual map-user is free to make his or her own personal associations with other landscapes (both real and imagined) and other cartographies. Within this particular geographical context, for example, the place-name of Coniston may evoke memories, for example, of an Ordnance Survey map showing the village of Coniston Cold in North Yorkshire; and, as a result, the practice may consist of the figurative layering of a recollected cartography on top of the material map which is near-at-hand. Alternatively, the geometric 
particularities of the contour lines which illustrate the gradient of the Cumbrian terrain may serendipitously remind the user of another map which represents a specific topography in a different county, country and perhaps even continent. The Ordnance Survey Explorer Map becomes emplaced and enmeshed within a subjective network of cartographic intertextuality and, as a result, this particular map can be read within the cultural context of all other cartographic representations of (the material and even imagined) landscape. An awareness of the intertextuality of cartography, therefore, reinforces the open-endedness and intrinsic subjectivity of mapping practices: each use constitutes a remaking of the map; and each map use unfolds within a series of interrelated and individuated intertextual contexts. It is a process which is enriched yet further if a map-user chooses to produce his or her own cartographical representations of geographical space. At the end of a walk, for example, a rambler may use a blank sheet of paper to sketch out a retrospective cartography of his or her completed route over, say, the Lake District fells. This production of a new personalised mapping contributes to the additional layering of the (geo-specific) cartographic palimpsest. Moreover, the shift from map-reading to map-making reinforces the processual ongoingness of mapping practices: practices which are always embodied and which always take place within the three-dimensional materiality of lived-space.

To return to the principal focus of this article, then, how can this concept of maps as processual intertexts be applied to literary cartographies? By extension, in what ways can this theoretical figuration chime with Thacker's movement towards a critical literary geography? To begin, it is important to register that literary maps function within the frameworks of at least three interpenetrating levels of intertextuality since, in addition to the two types of intertextuality (cartographic convention and geo-specific) embedded within an Ordnance Survey map, a third tier of intertextuality is provided by earlier literary cartographies. The intertextuality of literary maps, then, can be conceived of as a continuum. That is to say, some maps will appear to contain only the first category of intertextual allusion; whilst others might feature traces of all three types (cartographic, literary and geo-specific) of intertextuality. As well as acknowledging the intertextuality encoded within literary cartographies, though, it is possible for the spatial critic to draw upon the processual understanding of mapping practices to consider the ways in which these maps may be used and read: a critical move which offers a variant on Harley's suggestion that phenomenological reader-response theory might be used to open up further thinking about the process of map-reading (Harley, 2001, p. 242). As we have suggested, each individual 
mapping practice is founded upon the user's own necessarily subjective, and perhaps even idiosyncratic, intertextual associations: internalised connections which are ultimately impossible for the critical literary geographer to pre-empt or predict. The spatial critic can, however, reflect upon the ways in which the reader practises the intratextual relationship between the verbal and cartographic representations of space which appear between the covers of the published text. By extension, the spatial critic can consider how these readerly processes might inform the creation of reader-generated geo-visualisations which simultaneously map the topographic text and remap the original literary cartography. The limitation of textual space prevents us from drawing upon this concept of processual intertextuality to offer an extensive exploration of multiple variations of literary cartography. In the next section of the paper, however, we want to identify some of the ways in which this theory might work in critical practice by turning to a cardinal text within the canon of the cartographies of (semi-) fictional worlds.

\section{Authorial Mappings: The Literary Cartography of Arthur Ransome}

Arthur Ransome (1884-1967) was an English novelist, literary critic and journalist, who is best known for his 'Swallows and Amazons' series: twelve children's novels, published between 1930 and 1947, which are set in a range of semi-fictionalised geographical locations, including the Norfolk Broads, the Essex coast, the North Sea, the Hebrides, the Caribbean, the China Sea and, most famously, the English Lake District. The first novel in the sequence, Swallows and Amazons, narrates the outdoor adventures of the four Walker children - John, Susan, Titty and Roger - who are on holiday at Holly Howe: a farmhouse on the shores of an unidentified Cumbrian lake. ${ }^{3}$ The Walkers sail their dinghy, the Swallow, and set up camp on an island in the lake. It is here that the Walkers 'make war and then peace' (Hardyment, 2006, p. 19) with Nancy and Peggy Blackett: sisters whose family home is located nearby, at Beckfoot, and who are the self-proclaimed Amazon pirates of the novel's title. Conflict is followed by the formation of a coalition and, together, the Swallows and Amazons 'make peace and then war' (Hardyment, 2006, p. 19) with Uncle Jim: an aspiring author who is attempting to write in a houseboat on the lake and who, in an allusion to Robert Louis Stevenson's Treasure Island (1883), is given the name of Captain Flint by the children. The novel climaxes with a great storm and with the children returning to land to prepare for a new school year. The narrative is frequently predicated upon the children's blurring of reality and 
fiction as their encounters with the practice of everyday life in Lakeland - people, work, foodstuffs and so on - are habitually transformed, in their collective imagination, into the otherly and the fantastical. Saliently, the porosity which can be located in the children's perception of the actual and the imaginative can be similarly traced in Ransome's handling of the novel's geographical setting. In Swallows and Amazons, the distinction between material and fictional landscapes and places is collapsed as Ransome forges a new post-Romantic geography of the Lake District: a 'deliberate re-imagining of actual geography' (Brogan, 2004, p. 151) which partially emerges out of the conflation of two lakes, Coniston Water and Windermere, and the topographies to be found upon their respective shores.

The textual history of Swallows and Amazons is complex as Ransome articulated varying forms and degrees of dissatisfaction with the illustrations - drawn, first of all, by Steven Spurrier and later by Clifford Webb - commissioned by his publishers, Jonathan Cape. As a consequence, Ransome eventually decided to embed his own instantly recognisable' illustrations within his text: 'sparse, precise and carefully inked' drawings which, according to Geraint Jones in his notes to a special exhibition on Ransome's 'art' held in the summer of 2011, 'perfectly complement his [Ransome's] verb-centred prose' (Jones, 2011, p. 3). ${ }^{4}$ A similar process of 'textual morphology' shaped the use of maps in and around Ransome's text. ${ }^{5}$ Saliently, the first edition of Swallows and Amazons featured an endpaper map by Spurrier (see Figure 2): a map which Hugh Brogan, in a short eulogistic essay on Ransome's work, describes as 'a thing of beauty and wonder in itself' (Brogan, 2004, p. 150).

[Insert Figure 2 here: Spurrier's map.]

In later editions of Swallows and Amazons, however, Spurrier's map was replaced with what Brogan derisorily dismisses as 'a pedestrian, ill-drawn substitute' (Brogan, 2004, p. 150) produced by Ransome himself (see Figure 3): a process which underscores the imaginative importance that the novelist placed upon the relationship between textual and cartographical representations of geographical space.

[Insert Figure 3 here: Ransome’s later map.]

Perhaps more importantly, though, this process leads to a form of cartographic intertextuality within the palimpsestic textual history of Swallows and Amazons which, in turn, highlights the need for the spatial critic to stratify different forms of authorial mapping. 
If we follow Brogan's imaginative privileging of the original Spurrier map, in what ways can the concept of cartographic intertextuality be applied to Ransome's work? Most immediately, Spurrier's map draws upon cartographic traditions through the inclusion of, amongst other features, a suitably elaborate cartouche and a prominent compass rose. Although the narrative action of Swallows and Amazons is emplaced within a reconfigured version of the Lake District landscape, however, Spurrier's fictionalised mapping does not appear to feed off the geo-specific intertextual literary cartography of this corner of northwest England: a history of regional mapping which is most famously associated with the guide book tradition which began to emerge, with the development of Picturesque tourism, in the second-half of the eighteenth-century and which can be traced through to the mixedmedia innovations of Alfred Wainwright two hundred years later. ${ }^{6}$ Instead, the dominant intertextual sources for the Spurrier map are primarily literary. As Brogan argues, Ransome's literary map can be situated in a line of children's adventure narratives which can be tracked back to Robert Louis Stevenson's Treasure Island and which includes Rider Haggard's King Solomon's Mines (1886) and A. A. Milne's Winnie-the-Pooh (1926) (Brogan, 2004, p. 150): deliberately playful maps which, in the words of the American poet, Julie Larios, share poetry's potentiality for 'possibility, mystery, and riddle'; maps which offer readers 'a compass to find our way and then set us spinning around and around' under their spells (Larios, 2010, p. 21). As a result, the cartographic precursors for the Spurrier map exist beyond the geographic boundaries in which Ransome decides to situate, however loosely, his fictional narrative.

To read Swallows and Amazons is to engage with and in a suite of intersecting and overlapping mapping practices. Within the fictional world of the text, the Walker children are shown to be map-readers, in the Lake District guide book tradition, as they continuously turn to cartographies as they endeavour to situate themselves in their immediate locale. When the Walkers meet the Blackett girls, for instance, the most senior sibling, John, intuitively turns to the totalizing vision offered by an official cartography in order to imagine the precise location of the stone boathouse in which the Blackett boat, the Amazon, is kept: 'He got the guide-book and opened it at the map which showed the whole length of the lake' (Ransome, 2010, p. 130). Yet, crucially, the Walkers and the Blacketts instantaneously annotate this cartography and their personalised geography is layered on top of the 'official' (although, of course, fictionalised) place-names and symbols: 'Nancy Blackett showed him the river Amazon. It had another name on the map. John gave her the pencil. "You mark where the 
boathouse is," he said' (Ransome, 2010, p. 130). Beyond this, however, the Walkers are also map-makers as the charting of new territories forms a cartographic motif which runs throughout the novel: a trope which can be read in the imperialist terms which, as Brogan points out, dominates so much nineteenth- and twentieth-century British literary mapping (Brogan, 2004, p. 152). When confronted with Roger's anxiety regarding the apparent limitless of the environment in which they find themselves, John instinctively turns to the accumulative process of map-making to facilitate the ongoing understanding of place: "“It'll be years and years before we have been everywhere," said Roger. "We'll make a chart of our own," said John, "and every year we'll put in the part we have explored until we know it all", (Ransome, 2010, p. 78). As they explore their Lakeland environment, then, the Walker children evolve as map-makers whose practices seem to correspond, at least in part, with James Corner's proposition that mapping involves processes of 'gathering, working, reworking, assembling, relating, sifting' (Corner, 1999, p. 225). Mapping practices, therefore, are repeatedly performed within the imaginative space created by the fictional world.

Another type of intratextual processual practice, however, is enacted by the reader of the novel who, when working through the linear narrative, might continuously revisit the authorial cartography in an attempt to map out the fictionalised geography in his or her imagination. To return to the 1930 edition of Swallows and Amazons, then, the reader might intermittently return to the prefatory imaginative cartography in order to map out the Walkers' movement around Ransome's version of the Lake District. In one sense, the inclusion of this literary map encapsulates the paradox of cartography. According to Brogan, the power of Spurrier's map lies in its imaginative 'suggestiveness' and its capacity as an immediate visual signifier designed to 'excite and assist [the] readers' fancy' (Brogan, 2004, p. 150). Yet, simultaneously, the way in which the map prefaces the novel serves to contain, verify and authenticate the fictionalised geography delineated within the main body of Ransome's text; it allows the reader to 'locate' narrative events upon an authoritative, if equally imaginary, cartographical space. Although this process does not necessarily involve the creation of reader-generated maps, this experience is not merely passive: instead, the reader is actively moving - in both physical and imaginative terms - between textual and cartographic representations of space in an attempt to understand the topology of Ransome's fictionalised place. As with the characters within the text, then, the reader assumes the role of (literary) map-user; he or she shuttles back and forth between text and map, map and text. 
By extension, the reader may embark upon another type of mapping practice in which he or she moves beyond the textual space of the novel in order to consult other cartographies. According to Brogan, 'in the end it is of limited interest that [ . . ] Ransome made use of identifiable locations' in Swallows and Amazons as, ultimately, it 'is the process [of reimagining actual geographies] that counts' (Brogan, 2004, p. 151). Our emphasis on the processual intertextuality of literary maps clearly corresponds with this conceptualisation of Ransome's authorial cartographies; and Brogan's emphasis on the practice of literary mapmaking chimes with our own understanding of maps as always existing in a state of cominginto-being rather than as fixed referential systems. At the same time, however, there is a danger - in privileging the processual creation of imaginative geographies - of denying the instinct to read fictionalised mappings within the context of our own embodied experiences of particular places and alongside cartographies which do pertain to representational verisimilitude: an instinct which is exemplified, saliently, by the mapping practices showcased by the Walkers within the fictional world of the text. The reader of Swallows and Amazons, therefore, may read both Ransome's text and Spurrier's authorial cartography alongside, for example, an official Ordnance Survey map of the southern Lake District. That is to say, the consultation of a map which claims to offer representational fidelity may facilitate a further understanding of the ways in which Ransome's authorial cartographies offer a visual intertwining of the actual and the fictional. ${ }^{7}$

\section{Reader-Generated Mappings: Paper-Based Literary Cartography}

Some of the imbricated ideas regarding the nature of reader-response to Swallows and Amazons can be seen to converge upon the two-dimensional representational spaces of reader-generated literary mappings of Ransome's Lake District: cartographies which are, simultaneously, critical and creative maps; and cartographies which, in turn, produce an additional layer of cartographic intertextuality for the spatial literary critic to read and to interpret. In Arthur Ransome and Captain Flint's Trunk (2006), for example, Christina Hardyment sets out to locate the physical models for Ransome's imaginative geographies: 'Was there really a Wild Cat Island and a Swallowdale? Could we climb Kanchenjunga?' (Hardyment, 2006, p. 5). ${ }^{8}$ Strikingly, Hardyment's text is prefaced by a hand-drawn map which shows 'The Lakes in the North: Official Geography' (see Figure 4): a map which provides the proper place-names and road numbers for locations in and around the lakes at 
Coniston and Windermere. Cartographic intertextuality is evidenced by Hardyment's use of mapping conventions to symbolise such key locations as Ransome's grave at Rusland Church and the major fells in this corner of the Lake District; and the casually hand-drawn nature of the map serves to remind the reader that this is a cartography which has been made through a combination of cognitive and physical processes. At the other end of the book, a similar map is reproduced; but, in this instance, the 'Official Geography' is replaced with 'Ransome Geography' (see Figure 5) as the key imagined sites from Swallows and Amazons are located within the landscape of the southern Lake District. So, for example, the 'Ransome Geography' map places 'Wild Cat Island' at the southern end of a long lake which the 'Official Geography' cartography identifies as Windermere; whilst the fictional settlement of 'Rio' is placed on the location occupied by the tourist town of Bowness. Saliently, Hardyment draws explicit attention to the necessarily speculative nature of this mapping practice by providing the reader with a range of possible sites for important locations in Ransome's fictional world.

[Insert figures 4 and 5 here]

Hardyment's exercise in textual retracing is supplemented by two new cartographies which establish the spatial connections and disjunctions between the actual topography and Ransome's fictionalised geography. By extension, the reader of Arthur Ransome and Captain Flint's Trunk enters into a complex series of interlinked processes in which he or she might move, consciously or otherwise, between a range of reference points: a memory of the materiality of the Cumbrian landscape developed through the embodied experience of place; a sense of the overarching topology of the Lake District generated through an engagement with official maps of the region; a personal familiarity with the literary geography articulated in Swallows and Amazons; a knowledge of the examples of (intertextual) literary cartography embedded within Ransome's novel; a sense of how Hardyment's 'Official' cartography has been made through an individuated mapping practice; and an awareness of the ways in which the 'Ransome' map has been produced through Hardyment's own spatial interpretation of the novel.

A poster published by the Lake District Art Gallery and Museum Trust, however, offers an alternative to Hardyment's representational differentiation between 'official' and imaginative cartographies (see Figure 6). ${ }^{9}$

[Insert figure 6 here: Dalziel and Stockdale map] 
'Arthur Ransome in Lakeland' offers a hand-drawn map, designed by P. Dalziel and M. C. Stockdale, which places three types of mapping onto the one plane surface: the actual geography of the southern Lake District from Kendal in the east to Coniston in the west; the personalised, historical geography of Ransome's life in this area, including the sites at which he was schooled (Windermere) and in which he fished (River Winster); and the imaginative geography of his adventure novels for children, offering, for example, real-world locations for Holly Howe. In other words, it is a palimpsestic type of reader-generated literary mapping in which the geographical, historical and fictional intertwine and coalesce in the one representational space. There are clear correspondences with Hardyment's mapping of 'Ransome Geography' as, for example, 'Wild Cat Island' is once again located at Blake Holme at the southern end of Windermere and the cartography is oriented so that the west is placed at the top of the page. The Dalziel and Stockdale map, however, contains far more cartographic detail and offers the user a greater sense of the topographic particularities of this part of the Lake District including the heavily wooded terrain between Windermere and Coniston Water; the location of mines on the slopes of Coniston Old Man; and the line of the railway which brings passengers from the mainline station at Oxenholme.

\section{Reader-Generated Mappings: In-the-field Literary Cartography and the Role of Geospatial Technologies}

In a recent essay, Sheila Hones, suggests that, in spite of the growing interdisciplinary interest in critical literary geography, relatively little scholarly 'attention has been paid to the ways in which the reading process itself might be understood as a spatial practice' (Hones, 2011, p. 247). Hones begins to fill this perceived critical lacuna by positing a theoretical model of 'the novel as a spatial event' in which the 'lone reader' is understood to be 'spatially connected not only to a story, to a book, and to a text, but also to a narrator, an author, and a multitude of other readers, known and unknown, present and absent, near and far' (Hones, 2011, p. 247). Within the context of the present paper, Hones's 'idea of reading as a geographical process' (Hones, 2011, p. 247) carries a twin significance. First, her spatial analysis of the practice of novel-reading might be similarly applied to a user's engagement with literary maps; and her projection of an imagined, trans-historical community of readers corresponds with our own conceptualisation of the processual intertextuality of cartographies which emerges with each individual mapping practice. Alongside this, Hones's sensitivity to 
the importance of spatial contexts facilitates further thinking about the ways in which the geographical locatedness of the user might shape his or her response to literary cartographies: a sense of the reader as an embodied, situated presence which clearly informs the brand of literary fieldwork practised by Hardyment and which underpins the production of her readergenerated mapping of Ransome's fiction. In the final section of this paper we want to explore some of the ways in which geospatial technologies might be used in order to develop an understanding of how the place of reading might shape an embodied reader's response to both a literary text, such as Swallows and Amazons, and its associated cartographies. By extension, we want to suggest how the use of mobile technologies might enhance a reader's understanding of the processual intertextuality of maps and mapping practices by opening up a dynamic space in which new reader-generated literary cartographies might be made and presented.

First, how might mobile technologies provide users with different types of digital literary map to be consulted in-the-field? The development and use of maps on mobile devices has inevitably been driven, to date, by the imperatives of Location Based Services (LBS) to show a user's geographical position in relation to a range of local amenities; but how might such technologies be harnessed by a reader who wishes to engage with Ransome's Swallows and Amazons - and the existing forms of mapping related to that novel - whilst he or she is located in, and moves through, the Cumbrian landscape? Instantaneously, the Spurrier map presents representational challenges as that imaginative cartography does not neatly correlate with real-world geography. Crucially, however, a digitised version of the Spurrier map would allow the user to develop an experiential understanding of the disjunctions between the features of the textural topography and the Spurrier's fantastical geography. Moreover, this hand-held technology could be used to explore the relationships between an authoritative Ordnance Survey map, Spurrier's imaginative cartography, Ransome's text and earlier reader-generated mappings of that novel whilst they are physically situated within the landscape of the southern Lake District.

The use of mobile devices to explore authorial and extant reader-generated literary maps, then, could perhaps be seen as one example of what Joliveau (Joliveau, 2009, p. 36) refers to as 'intermediary territory' where geospatial technology acts as an integrating platform for connecting multiple forms and modes of (real and fictionalised) landscape representation. The use of hypermedia to geographise literary texts is becoming increasingly prevalent through smartphones and tablets: a popularity which is illustrated by Penguin's 
iPad 'app' in which Jack Kerouac's semi-autobiographical Beat Generation novel, On the Road (1957), is enhanced by the presentation of rich interconnected media content including digital mappings of the protagonists' road trips across the United States. Although this app opens up potential for linking literature and landscape whilst the user is on location, however, there remains space to make literary hypermedia truly locative. That is to say, there is scope for projects to present literary hypermedia (primary texts, authorial maps, existing readergenerated cartographies and so on) in a geo-referenced format so that this information can be automatically delivered to a smartphone when a user enters a predetermined 'trigger' zone. Experiments such as the 'textopia' project led by Anders Løvlie - in which literary texts are automatically delivered to mobile users through locational triggers - 'allow readers and writers to see literature in relation to their lived environment' and might even 'contribute to a vision of public spaces as inherently readable, playable and malleable by its inhabitants' (Løvlie, 2009, p. 28). Such systems are not without their problems and Løvlie discusses the implications, for the user experience, of imposing trigger zones which are either too large or too small in geographical scale; but, in spite of such technical challenges, 'textopia' serves to remind users of the fact that even literary maps are inextricably embedded within - and not divorced from - the material world of quotidian spatial practice.

So far, we have touched upon the possibilities and problems associated with users receiving information whilst they are located in-the-field; but, clearly, there is also enormous potential for enabling users to create their own maps based upon their reading of literary texts and associated cartographies. Critical literary geographers, in both Europe and the United States, have begun to explore the visualisation and interpretative potentialities offered by the use of desktop GIS technologies in order to produce reader-generated mappings of geospecific literary texts: the 'Mapping the Lakes' project, for instance, has employed GIS to chart two canonical examples of Lake District landscape writing; and a similar methodology has underpinned the more ambitious work on the 'Literary Atlas of Europe'. ${ }^{10}$ Mapping in the age of the internet, however, can assume many forms as digital technologies offer a range of new opportunities for both the production and use of literary cartographies. Ubiquitous web-based 'slippy maps' (such as Google Maps), and virtual globes (such as Google Earth), open up new mapping practices in that they allow the user to engage in the intuitive, and even playful, dragging and zooming of digital map data; they present aerial imagery; and they provide space for the presentation of alternative representations of landscape, including the layering of historical maps, which, in turn, serve to highlight the intertextuality of 
cartography. Such technologies, which offer unprecedentedly privileged views of the Earth's surface, complement the analytical power of desktop GIS through the use of interactive visual tools which are increasingly familiar to the general public. By extension, then, such technologies provide a useful graphical frontend for reader-generated digital cartography projects such as 'Mapping the Lakes'; and they provide a flexible digital environment for the further layering of representations of space and place (including other texts, landscape paintings and so on) through addition of hypermedia links. Yet, in spite of such innovations, there remains a need to move reader-generated literary mapping practices beyond the desktop in order to examine how digital technologies might support the type of in-the-field literary geography showcased by Hardyment.

In order to test such digital potentiality it is necessary to turn to the ways in which geospatial technologies - and, more particularly, GPS-enabled devices - have been used in other fields and other exploratory projects. User-generated digital mapping remains in its infancy and, at present, does not guarantee the completeness of geographical coverage offered by the Ordnance Survey: an issue which is discussed by Haklay and Weber (2008) in relation to the OpenStreetMap project. What is of interest, however, is the way in which such technologies empower the user with a GPS receiver to inform the map-making process by contributing to a free global, spatial database and by correcting extant cartographic features. With GPS embedded within many mobile telephones, and with the increasing prominence of the 'app' in the popular consciousness, there are clear opportunities for the further exploration of new creative and locative mapping processes: practices which utilise, in turn, the merits of hypermedia to connect audio and textual comments, images and videos, to geographical locations on the ground. Current mobile mapping tools tend to record GPS trails, along with the locations of photographs or notes, as 'pins' typically placed against the backdrop of a generic cartography. Beyond this, however, a key research challenge is to consider the construction and re-presentation of egocentric maps which emerge from various combinations of user-generated content and authorial survey: transitory digital representations generated 'on the fly' according to the user's interests, activities and intentions, formed from dynamically generated symbols that reflect both the digital content and its relevance to the user. As Thielmann (2010) points out, the increasing centrality of ideas of location and place in web-based and mobile information services is currently promoting greater interdisciplinary interest in media geographies. Also, as Perkins (2007) observes, geospatial technologies have the ability to empower individuals and communities 
through the construction and sharing of both personal and collective mappings: not only of conventionally mapped objects, such as roads and buildings, but of mood or the emotional attachment to place. The challenge remains, however, as to how such user-generated mapping practices - based upon embodied geographical experiences and subjective responses to space and place - might inform the creation of reader-generated literary maps.

The potentiality of such digital literary mapping practices can be illustrated further by turning to recent pedagogic research on geographical fieldwork: research which transcends the limitations of fixed-point, plane-view digital cartographies by focusing on the ways in which geospatial visualisations might correspond with the landscape views opened up to an embodied subject as he or she moves through the topography. Whilst geospatial technologies can be used to streamline data logging, or to deliver field notes, we have focused on designing projects that address the research challenges presented by the use of locative media in a broad landscape setting. Authoring environments for creating mediascapes, such as Mscape (Stenton et al, 2007), have allowed great flexibility in the way media experiences can be designed in-the-field, driven primarily by locational triggers. Some studies have begun to explore the use of trigger regions for media based on the area visible from a particular location (Møller-Jensen and Egler Hansen, 2007); and Bartie et al (2008) offer a detailed analysis of visibility metrics for predicting when a range of urban landmarks would become visible in the landscape and, by extension, when media relating to those sites might be delivered. Such studies have focussed on filtering information to be delivered to a mobile user; but such techniques may also offer interesting ways to encode the broader landscape area that may be of relevance when capturing a note, for example, or a sketch. An example of a pedagogic project which explores the utility of geospatial technologies in such contexts is the comparative study of a range of techniques for augmenting a visitor's experience of the surrounding topography in the Lake District presented in Priestnall et al (2009). In addition to a conventional mediascape using positional triggers, one of the key techniques tested was a custom locative application which delivered media according to the area which was visible from the where the user was standing. Saliently, this application also featured an on-screen sketch facility: a facility which is illustrated in Figure 7 and which is described in detail by Priestnall and Polmear (2006). The analysis of video diaries and focus group discussions generated pedagogic findings which are clearly germane to the adoption of geospatial technologies in a literary fieldwork context. For instance, the ability to capture notes and sketches - relating to both the immediate landscape and the media which had been made 
available at a particular location - successfully aided the students' field observations. By extension, then, the process of using such technologies to capture a richer sense of the user's in-the-field experience is of great value to the critical literary geographer interested in the reading of literary texts and maps as a phenomenological 'spatial event'. More specifically, the capacity to produce user-generated digital content allows users to follow Hardyment's example by making their own reader-generated literary maps. Research into such processes would, in turn, satisfy the need for greater observation of the use of various forms of cartography in field settings: a key trope which the manifesto for map studies proposed by Dodge et al (2009).

[Insert Figure 7 here: Sketch tool with a mobile application.]

A location-aware hypermedia system, therefore, offers a platform for exploring the processes involved with capturing, re-working and portraying literary mappings which mix authorial content with user-generated reflections. The final 'outputs' of such research could be seen to be new cartographies in which the user maps out actual and/or imaginative geographies based upon his or her reading of a particular topographic text: a cartographic product which would provide a digital version of the 'Ransome Geography' map published in Hardyment's critical-creative monograph; but which, crucially, could be displayed alongside - or on top of - extant (literary) maps to add a further, and finely granulated, layer of cartographic intertextuality. Perhaps more importantly, though, the devices would also store the processes involved in the production of these new reader-generated maps, including the physical movements - in and across space and time - of individual readers. As a result, the integration of location-aware hypermedia systems into the work of the spatial critic might open up new forms of literary cartography which are simultaneously sensitive to the (textual and cartographic) intertextuality of particular places and are predicated upon the reader's phenomenological immersion in a specific landscape and environment.

\section{Conclusion: Towards Literary Fieldwork}

In conclusion, then, what methodological, conceptual and critical possibilities might be opened up by the movement of digital literary cartography from desktop GIS to technologies which can be used in-the-field? To return to Swallows and Amazons, the capacity to place different types of authorial and reader-generated cartographies onto a single platform, 
alongside Ransome's text, has the potential to enrich the spatial critic's understanding of both the complex relationship between actual and imaginative geographies and the multi-layered creative-critical (re-) mapping of the area around Coniston and Windermere. Crucially, such processes will unfold within the landscape itself as the critic follows Hardyment's strategy of retracing the imagined movements of the Walker children across the material reality of the Lake District topography. At the same time, the interwoven practices of in-the-field literary map-reading and map-making will clearly have wider applications and implications. The use of such digital technologies will enhance the genuine interdisciplinarity of contemporary approaches to literary cartography and, through the use of multi-media platforms, will carry the potential to bring together scholars from literary studies, geography and visual arts, to list just three subject areas, whose research interests converge on the imaginative representation of a particular named landscape. The representational limitations of the screen are not unproblematic; but, at the same time, the creation of reader-generated maps within this necessarily confined (re)presentational space will prompt the spatial critic to reflect further upon, through embodied experience, the complexities of cartographic practices and processes ${ }^{11}$. Ultimately, then, the use of digital technologies points the way towards future developments in literary fieldwork practices. Moreover, these developments which will be predicated upon an enhanced awareness of, and contribution to, the processual intertextuality of literary maps: the way in which literary maps are textual systems of signification and association which are always practised within a spatial context.

\footnotetext{
11 The small screen on mobile phones may prompt the return to an efficiency of portrayal reminiscent of more traditional drawings. Some current research on rural mobile mapping involving the Ordnance Survey has suggested a portrayal of GPS routes and associated points of interest which draws inspiration from the 'strip map' style of road maps by John Ogilby. Similarly there are already examples of mobile portrayals which draw inspiration from earlier designs, for example the panorama style representations used by the 'Viewranger' app by Augmentra. (http://www.viewranger.com)
}

\section{References}

Bartie, P. J., Mills, S., Kingham, S. (2008) An Egocentric Urban Viewshed: A Method for Landmark Visibility Mapping for Pedestrian Location Based Services, in Geospatial Vision:

New Dimensions in Cartography, ed. by Moore, A. and Drecki, I., pp 61-85, Springer, Berlin. 
Bate, J. (1991). Romantic Ecology: Wordsworth and the Environmental Tradition, Routledge, London.

Brogan, H. (2004). 'The Lure of Maps in Arthur Ransome', in You Are Here: Personal Geographies and Other Maps of the Imagination, ed. by Harmon, K., pp. 150-3, Princeton Architectural Press, New York.

Carlson, J. S. (2010). 'Topographical Measures: Wordsworth's and Crosthwaite's Lines on the Lake District', Romanticism, 16, pp. 72-93.

Cooper, D. and Gregory, I. N. (2011). 'Mapping the English Lake District: A Literary GIS', Transactions of the Institute of British Geographers, 36, pp. 89-108.

Corner, J. (1999). 'The Agency of Mapping: Speculation, Critique and Invention', in Mappings, ed. by Cosgrove, D., pp. 213-53, Reaktion Books, London.

Dodge, M., Perkins, C. and Kitchin. R. (2009). 'Mapping Modes, Methods and Moments: A Manifesto for Map Studies, in Dodge, M., Kitchin. R. and Perkins C. (Eds). Rethinking Maps: New Frontiers in Cartographic Theory, pp. 220-43, Routledge, London.

Dodge, M., Kitchin. R. and Perkins, C. (Eds). (2009). Rethinking Maps: New Frontiers in Cartographic Theory, Routledge, London.

Edwards, J. (2006). Writing, Geometry and Space in Seventeenth-Century England and America, Routledge, London.

Gregory, I. N. and Cooper, D. (2009). 'Thomas Gray, Samuel Taylor Coleridge and Geographical Information Systems: A Literary GIS of two Lake District Tours'.

International Journal of Humanities and Arts Computing, 3, pp. 61-84.

Haklay, M., and Weber, P. (2008). 'OpenStreetMap: User-Generated Street Maps', IEEE Pervasive Computing, 7, pp. 12-18.

Hardyment, C. (2006). Arthur Ransome and Captain Flint's Trunk, Frances Lincoln, London.

Harley, J. B. (2001). The New Nature of Maps: Essays in the History of Cartography, Johns Hopkins University Press, Baltimore. 
Hones, S. (2011). 'Literary Geography: The Novel as a Spatial Event', in Envisioning Landscapes, Making Worlds: Geography and the Humanities, ed. by Daniels, S., DeLyser, D., Entrikin, J. N. and Richardson D, pp. 247-55, Routledge, London.

Hunt, P. (1991). Approaching Arthur Ransome, Jonathan Cape, London.

Jameson, F. (1991). Postmodernism, or the Cultural Logic of Late Capitalism, Verso, London.

Jones, G. (2011). 'Introduction', in Imagination and Reality: The Art of Arthur Ransome, pp. 3-4, Brantwood, Coniston.

Joliveau, T. (2009) 'Connecting Real and Imaginary Places through Geospatial Technologies?: Examples from Set-jetting and Art-oriented Tourism', The Cartographic Journal, 46, pp.36-45.

Kitchin, R., Perkins, C. and Dodge, M. (2009). 'Thinking about Maps', in Rethinking Maps: new Frontiers in Cartographic Theory, ed. by Dodge, M., Kitchin, R. and Perkins, C., pp. 1-25, Routledge, London.

Larios, J. “"Harbours That Pleased Me Like Sonnets": On the Pleasures of Literary Maps', The Horn Book Magazine, May/June 2010, pp. 20-5.

Løvlie, A.S. (2009) 'Poetic augmented reality: Place-bound Literature in Locative Media'. Proceedings of the 13th International MindTrek Conference: Everyday Life in the Ubiquitous Era, Tampere, Finland, 19-28.

Møller-Jensen, L. and Egler Hansen, J. (2007). 'Towards a Mobile Tourist Information System: Identifying Zones of Information Relevance'. Proceedings of the 10th AGILE International Conference on Geographic Information Science 2007, Aalborg University, Aalborg.

Moretti, F. (1998). Atlas of the European Novel 1800-1900, Verso, London.

Perkins, C. (2007) 'Community Mapping'. The Cartographic Journal, 44, pp. 127-137.

Priestnall, G., Brown, E., Sharples, M., and Polmear, G. (2009). 'A student-led comparison of techniques for augmenting the field experience'. Proceedings of Mlearn 2009, Orlando, Florida, October 28th - 30th 2009. 
Priestnall, G. and Polmear, G. (2006). 'Landscape Visualisation: From Lab to Field'. Proceedings of the First International Workshop on Mobile Geospatial Augmented Reality, Banff, Alberta, 29-30 May 2006.

Ransome, A. (2010) Swallows and Amazons, Red Fox, London.

Stenton, S.P., Hull, R., Goddi, P.M., Reid, J.E., Clayton, B.J., Melamed, T.J., and Wee, S. (2007). 'Mediascapes: Context-Aware Multimedia Experiences'. IEEE Multimedia, 14, pp. 98-105.

Thacker, A. (2005/6). 'The Idea of a Critical Literary Geography', New Formations, 57, pp. $56-73$.

Thielmann, T. (2010) 'Locative Media and Mediated Localities'. Aether: The Journal of Media Geography 5, pp. 1-17. 
1 The terms, 'authorial' and 'reader-generated mappings', are synonymous with the labels 'writerly' and 'readerly mappings' which were used in an earlier publication on the possibilities of literary GIS (Cooper and Gregory, 2011 , p. 91) but which, on reflection, perhaps carry distractedly post-structuralist connotations.

${ }^{2}$ This definition of authorial mapping needs to be problematised, and enriched, in ways which cannot be fully explored within the parameters of the present paper. That is to say, a series of additional sub-categories need to be identified in order to distinguish between, for instance, a writer's use of maps and mapping practices in the compositional process (as evidenced, for example, by the inclusion of cartographic doodlings in his or her notebooks); the inclusion of a writer's own maps in the published text; and the insertion of new cartographies - produced by a third-party - which have been commissioned by the editor/publisher and perhaps even without the absolute approval of the author of the text. The distinction between the final two cartographic categories is especially important in tracing the genealogy of the topographic illustrations to be found in the novels of Arthur Ransome.

${ }^{3}$ For a detailed synopsis of Swallows and Amazons, see Peter Hunt's Approaching Arthur Ransome (1991).

4 The complex textual history of the illustrations and sketches in Swallows and Amazons was the subject of 'Imagination and Reality: The Art of Arthur Ransome': a special exhibition held at Brantwood, Coniston - the former home of the Victorian polymath, John Ruskin - between May and September 2011.

${ }^{5}$ Jonathan Bate uses the term, 'textual morphology', when discussing the complex publication history of a key text in the history of Lake District topographic writing: William Wordsworth's prose Guide to the Lakes (Bate, 1991, p. 44).

6 For a consideration of the relationship between cartographic and textual practices in eighteenth-century representations of the Lake District, see Julia S. Carlson (2010). Carlson's work opens up critical space for a detailed history of literary map-making within the Lakes: a history which would necessarily involve an extensive critical analysis of the way in which Wainwright uses a range of geo-visualisation techniques in what might be described as his lifelong work of 'environmental autobiography' or his 'deep mapping' of region.

${ }^{7}$ The reader's instinct to identify locatable places in Ransome's writings is exemplified by the 'Resources' page on the website of the Arthur Ransome Society. Amongst the resources presently under development is a facility to discover 'some of the real places Ransome used in his books'. http://www.arthur-ransome.org/ar/swallows-and-amazons [accessed 3 June 2011].

${ }^{8}$ Hardyment's work on Arthur Ransome feeds into a wider sub-genre of contemporary landscape writing: a process of retracing actual and imaginative (literary) presences which moves across the permeable boundary between critical and creative non-fiction practices.

${ }^{9}$ In 1992, the Lake District Art Gallery and Museum Trust was superseded by the Lakeland Arts Trust.

10 The British Academy-funded project, 'Mapping the Lakes' (www.lancaster.ac.uk/mappingthelakes), was based at Lancaster University and was co-ordinated by Ian Gregory and David Cooper. For detailed technological and critical discussions of the project see Gregory and Cooper (2009); and Cooper and Gregory (2011). The 'Literary Atlas of Europe' project was run by Lorenz Hurni and Barbara Piatti at the Institut für Kartografie, Zürich (http://www.literaturatlas.eu/index_en.html). 